\title{
DIAGNÓSTICOS DE ENFERMAGEM NUMA GESTANTE DE ALTO RISCO BASEADOS NA TEORIA DO AUTOCUIDADO DE OREM: ESTUDO DE CASO*
}

\author{
Maria do Carmo Andrade Duarte de Farias** \\ Maria Miriam Lima da Nóbrega***
}

FARIAS, M.C.A.D. de; NÓBREGA, M.M.L. da. Diagnósticos de enfermagem numa gestante de alto risco baseados na teoria do autocuidado de Orem: estudo de caso. Rev.latino-am.enfermagem, Ribeirão Preto, v. 8, n. 6, p. 5967 , dezembro 2000 .

Trata-se de uma pesquisa descritiva com uma abordagem qualitativa, realizada objetivando identificar diagnósticos de enfermagem numa gestante de alto risco, baseados na teoria do autocuidado, de Orem. Foram identificados os seguintes diagnósticos de enfermagem: déficit de volume de líquidos, ansiedade, processo familiar alterado, comunicação prejudicada, mobilidade física prejudicada, entre outros. Os resultados mostraram a importância da execução do processo de enfermagem, apoiado num modelo de assistência, para a identificação de diagnóstico de enfermagem, bem como a viabilidade da paciente engajar-se no autocuidado.

UNITERMOS: diagnóstico de enfermagem, gravidez de alto risco, autocuidado

\section{INTRODUÇÃO}

A ciência da enfermagem está pautada numa ampla estrutura teórica e, o processo de enfermagem, segundo IYER et al. ${ }^{5}$, é "o modelo através do qual essa estrutura é aplicada à prática da enfermagem". Assim, sendo o processo de enfermagem o cerne da profissão, é importante a sua utilização na assistência ao paciente, para nortear a prática da enfermagem. Porém, necessário é que este processo seja embasado numa teoria de enfermagem, para que possibilite não apenas nortear a sua prática, bem como viabilizar e tornar concretos os resultados dessa assistência. Na execução do processo de enfermagem o autocuidado deve ser um dos objetivos, para que o paciente seja estimulado a participar de forma ativa na terapêutica, tornando-se correspondente na condução e nos resultados da assistência. Foot et al. citados por PEIXOTO", "afirmam que a teoria de OREM fornece uma estrutura para uma enfermagem holística, nos aspectos relativos ao levantamento e interpretação de dados".

São vários os trabalhos realizados pela enfermagem utilizando a teoria do Autocuidado de Orem na assistência aos mais diversos pacientes, haja vista que este modelo teórico facilita o planejamento da assistência e mostra-se efetivo e eficaz, pois leva o paciente a engajarse no autocuidado.

Esta pesquisa foi realizada com uma gestante de alto risco, com diagnóstico médico de placenta prévia, através da implementação do processo de enfermagem embasado na teoria de OREM, possibilitando a identificação de diagnósticos de enfermagem, que são imprescindíveis no planejamento da assistência, uma vez que eles nortearão as intervenções de enfermagem. Em conseqüência, o acompanhamento à gestante será eficaz, pois as ações serão voltadas para as suas peculiaridades, visando a redução dos déficits de $\mathrm{AC}$, na busca de contribuir para a redução do índice de morbimortalidade materna.

Justifica-se também a realização deste estudo em virtude da placenta prévia ser uma das principais patologias determinantes de morte materna, tendo em vista a hemorragia que proporciona. Esta, associada às infecções e a toxemia, são responsáveis por $50 \%$ das mortes maternas em todo o mundo, sendo passíveis de prevenção primária ${ }^{6}$. Um caminho para a prevenção seria

\footnotetext{
* Trabalho apresentado no III Simpósio Nacional sobre Diagnóstico de Enfermagem e I Encontro Cearense sobre Diagnóstico de Enfermagem, em novembro de 1996, Fortaleza - Ceará

** Enfermeira. Docente da Universidade Federal da Paraíba, CFP/Campus V. Mestre em Enfermagem/UFPB. Endereço: Rua: Barão de Aratanha, 667 - Centro - 60050-070 - Fortaleza - Ceará - Brasil

*** Enfermeira. Mestre em Enfermagem pela UFPB. Docente do Departamento de Enfermagem de Saúde Pública e Psiquiatria, CCS/UFPB. Orientadora da pesquisa
} 
o engajamento e a prática do autocuidado, tendo por base o conhecimento da gestante acerca do seu problema, fatores determinantes e preditivos a ele associados, que acreditamos seja possível de ser alcançado através da operacionalização do processo de enfermagem.

\section{OBJETIVO}

Identificar diagnósticos de enfermagem numa gestante de alto risco, baseando-se na teoria do autocuidado de OREM.

\section{REFERENCIAL TEÓRICO}

\subsection{A gestação e a placenta prévia}

A gestação é caracterizada por alterações fisiológicas, físicas e emocionais, vivenciadas de forma distinta por cada mulher. Essas alterações são decorrentes de fatores hormonais e mecânicos, e devem ser considerados normais durante o estado gravídico. Conquanto, há alguns fatores que tornam a gestação de alto risco, para a mãe, para o concepto, ou para ambos, a exemplo da placenta prévia ${ }^{9,10}$.

Como a gestação é marcada por etapas de desenvolvimento, a gestante precisa ser acompanhada sistematicamente durante a evolução da gravidez, com vistas a atender as suas necessidades, obtendo assim melhores resultados sobre a sua saúde e do recém-nascido.

Durante o acompanhamento da gestante, os profissionais da saúde devem realizar intervenções preventivas, educativas e terapêuticas, tais como exames físico e obstétrico, vacinação, solicitação de exames de rotina, entre outras; ao passo que, de acordo com os dados obtidos e as necessidades, a gestante deve ser orientada, incentivada e ajudada a realizar o autocuidado necessário. Ressalta-se a relevância destas intervenções, tendo em vista que um outro ser está sendo formado, e que, se estes cuidados não forem efetivados, mãe e filho correm risco de vida ${ }^{3}$.

No caso de uma gestante de alto risco, em particular com placenta prévia, estes cuidados devem ser intensificados e monitorizados, pois este diagnóstico é um dos principais fatores de prematuridade e letalidade materna ${ }^{10}$.

Na placenta prévia a placenta está implantada no canal cervical, que não é o sítio normal de implantação placentária. A cérvix, no terceiro trimestre de gestação, modifica-se intensa e gradualmente, ocasionando hemorragia placentária. Caso não aja interferência terapêutica, pode provocar grandes perdas sangüíneas, superando a capacidade de reação orgânica compensatória, podendo levar a óbito materno ${ }^{2}$.

\subsection{A teoria geral de enfermagem de DOROTHEA OREM}

A Teoria de Enfermagem de Orem é formada por três constructos teóricos que são relacionados entre si: a Teoria do Autocuidado (AC), a Teoria do Déficit de Autocuidado e a Teoria dos Sistemas de Enfermagem ${ }^{1}$.

Para $\mathrm{OREM}^{7}$, o AC é "a prática das ações que os indivíduos iniciam e executam por si mesmos para manter, promover, recuperar e/ou conviver com os efeitos e limitações dessas alterações de saúde, contribuindo assim para sua integridade, funcionamento e desenvolvimento".

As capacidades de autocuidado são as habilidades que o indivíduo possui, que o faz realizar as suas atividades de autocuidado. Essas habilidades estão condicionadas a uma série de fatores, como o sexo, a idade, estado de desenvolvimento, condições sócioeconômicas e culturais, nível educacional, estado de saúde e experiência de vida ${ }^{4}$.

As demandas terapêuticas de autocuidado, segundo Orem citada por PEIXOTO ${ }^{8}$, são as ações necessárias e confiáveis para controlar tudo o que prejudica o desenvolvimento e a regulação do corpo humano. Essas ações diferem em seus aspectos, na sua constituição e estabilidade, conforme os requisitos de autocuidado que lhes deram origem. Esses requisitos são classificados em universais - comuns a todos os indivíduos, em todos os seus estágios de desenvolvimento; de desenvolvimento - relacionados as etapas do desenvolvimento humano e com os fatores intervenientes; e de desvios de saúde - relacionados aos problemas de ordem funcional, genética, bem como o diagnóstico médico e meios de tratamento.

A Teoria do Déficit de Autocuidado segundo FOSTER \& JANSSENS ${ }^{4}$, é o substancial da Teoria de OREM, pois é nela que se mostra quando a enfermagem é necessária. O déficit de $\mathrm{AC}$ ocorre, quando as habilidades de autocuidado do indivíduo são insuficientes para satisfazer as suas demandas terapêuticas de AC. Nesse caso, o enfermeiro atua como provedor de AC.

Na visão de Orem citada por PEIXOTO ${ }^{8}$, após o enfermeiro identificar os déficits de AC, ele estabelece o plano de ação junto ao paciente, delegando a sua responsabilidade, a do paciente e a de outros profissionais, para que as demandas terapêuticas para o AC sejam atendidas. 
$\mathrm{Na}$ Teoria dos Sistemas de Enfermagem, Orem citada por FOSTER \& JANSSENS ${ }^{4}$, classificou três sistemas de enfermagem para que os requisitos de $\mathrm{AC}$ do paciente possam ser atendidos: •o Sistema Totalmente Compensatório, ao qual o paciente é incapaz de realizar o autocuidado, pois as suas ações são limitadas; - o Sistema Parcialmente Compensatório, onde o enfermeiro e o paciente realizam medidas de cuidado; - o Sistema Apoio-educação, onde o paciente realiza e regula suas atividades de autocuidado. $\mathrm{O}$ enfermeiro o auxilia para que ele seja um agente de autocuidado.

$O$ processo de enfermagem de OREM compreende as fases de diagnóstico e prescrição, planejamento, produção e administração. Neste processo são determinados os déficits de autocuidado e definidos os papéis do paciente e do enfermeiro para que as exigências de autocuidado sejam atendidas ${ }^{4}$.

\section{METODOLOGIA}

Trata-se de um estudo descritivo, com uma abordagem qualitativa, do tipo estudo de caso. Para a coleta de dados foi realizada uma entrevista semiestruturada, utilizando um roteiro que enfocava os seguintes aspectos da teoria de OREM: levantamento de fatores condicionantes, demandas terapêuticas para o $\mathrm{AC}$, capacidades e habilidades do paciente para atender essas demandas, e os déficits de autocuidado (Anexo 1). Antes da realização da pesquisa foi solicitada a anuência por escrito da gestante para participar do estudo, de acordo com a Resolução 01/1998, do Ministério da Saúde, Capítulo II - Aspectos Éticos da Pesquisa em Seres Humanos $^{11}$. A pesquisa foi realizada inicialmente no domicílio da paciente, e posteriormente na maternidade onde a mesma foi submetida a uma cesária de emergência. A paciente foi acompanhada por quatro dias sucessivos, nos quais, diariamente era realizada a sua avaliação e identificados os déficits de autocuidado, bem como os respectivos diagnósticos de enfermagem. Para realizar a identificação dos diagnósticos de enfermagem adotouse o processo de raciocínio diagnóstico de Gordon citado por IYER et $\mathrm{al}^{5}$. A partir da identificação dos diagnósticos de enfermagem, primeira fase do processo de Orem, foi traçado o planejamento da assistência de enfermagem quando foram determinadas as metas, os objetivos, o método de ajuda, o tipo de sistema de enfermagem e estabelecido as intervenções de enfermagem. Esse planejamento passou por modificações de acordo com as avaliações que foram feitas na cliente durante o estudo. Todas as etapas do processo foram implementadas tendo como meta primordial levar a paciente a realização do autocuidado.

\section{RESULTADOS E DISCUSSÕES}

\subsection{Aplicação da teoria de OREM ao processo de enfermagem}

\subsubsection{História da paciente}

A senhora V., brasileira, casada, funcionária pública federal, graduada em Ciências Contábeis, 30 anos, $1,56 \mathrm{~m}$, pesando $64 \mathrm{Kg}$, grávida do $2^{\circ}$ filho, no $8^{\circ}$ mês. Seu $1^{\circ}$ filho tem 1 a e $9 \mathrm{~m}$. No $5^{\circ}$ mês desta $2^{\mathrm{a}}$ gestação apresentou pequeno sangramento vaginal, que, após ultrasonografia foi diagnosticado placenta prévia, levando-a a repouso absoluto, a conselho médico. No momento não apresenta sangramento. O parto será do tipo cesária, que está agendado para o dia 07 de agosto. $\mathrm{Na}$ cirurgia será retirado o seu único ovário, que ora apresenta-se com cisto dermóide acentuado. O seu outro ovário foi retirado aos seus quinze anos. Conhece a importância da placenta para a criança, bem como os fatores de risco da placenta prévia. Atualmente está estudando para o concurso do TRT. Ela acredita que a sua aprovação nesse concurso trará melhoria para a sua vida. Apresenta-se apreensiva em relação ao mesmo, e relata que tem sonhado com a prova, e que os sonhos não são bons. Este fato, associado à cirurgia a tem deixado preocupada. Ela teme a recuperação do parto (cirurgia), pois não vai ser como no primeiro parto, o qual foi normal. Sabe que não vai poder segurar o seu $1^{\circ}$ filho no colo, aliás, já não o segura desde a detecção da placenta prévia. Outro fator que tem causado "angústia" (sua fala) é estar morando na casa da família, onde sua privacidade para conversar com o marido é restrita, e não pode cuidar do filho (devido ao seu problema de saúde e porque muitos interferem). Relata que após ter sido diagnosticado a placenta prévia, o ritmo de vida do seu filho mudou, principalmente o horário de dormir. Deseja modificar esse horário, para no próximo ano colocá-lo na escola. Conta com a ajuda de uma prima para cuidar do seu filho. Às vezes, a $\mathrm{Sr}^{\mathrm{a}}$. V. passa o final de semana na casa dos sogros, ou até uma semana. Vê televisão à noite. Dorme de 7 a 8 horas por dia, acorda durante a noite com a barriga incomodando, mas logo adormece. Bebe cerca de 1 litro de água por dia, tem história de hemorróidas na última gravidez, e alimenta-se de forma balanceada, em horários freqüentes e regulares. Durante o dia elimina fezes uma vez e urina várias vezes, em boa quantidade. Fez exames laboratoriais recente, os dados estão todos dentro dos limites. Apresenta-se bem vestida. 


\subsubsection{Planejamento da assistência de enfermagem}

\begin{tabular}{|c|c|c|c|c|c|c|c|}
\hline ATENDIMENTO & $\begin{array}{c}\text { DÉFICIT NO } \\
\text { AUTO CUIDADO }\end{array}$ & $\begin{array}{l}\text { DIAGNÓ STICODE } \\
\text { ENFER MAGEM }\end{array}$ & METAS & OBJEHVOS & $\begin{array}{l}\text { MÉTODO } \\
\text { DEAJUDA }\end{array}$ & $\begin{array}{l}\text { TIPO DE } \\
\text { SISTEMA }\end{array}$ & $\begin{array}{l}\text { INTER VENÇŎES DE } \\
\text { ENFER MAGEM }\end{array}$ \\
\hline $1^{*} \mathrm{dia}$ & $\begin{array}{l}\text { Ingestão de líqui- } \\
\text { dos. }\end{array}$ & $\begin{array}{l}\text { Déficitdo volume de } \\
\text { líquido relacionado a } \\
\text { diminuiçãoda ingesta } \\
\text { de líquidos. }\end{array}$ & $\begin{array}{l}\text { Levar a } \\
\text { gestante } \\
\text { a: } \\
\text { - Reco- } \\
\text { nhecer a } \\
\text { importan- } \\
\text { cia da in- } \\
\text { gesta de } \\
\text { liquidos e } \\
\text { comeqien- } \\
\text { temente } \\
\text { aumentar } \\
\text { esta in- } \\
\text { gesta. }\end{array}$ & $\begin{array}{l}\text { Levar a ges- } \\
\text { tante a: } \\
\text { - Verbalizar } \\
\text { que reconhece } \\
\text { aimportância } \\
\text { da ingesta de } \\
\text { líquidos para } \\
\text { oorganismo. }\end{array}$ & Ersinar. & $\begin{array}{l}\text { A poio - } \\
\text { educação. }\end{array}$ & 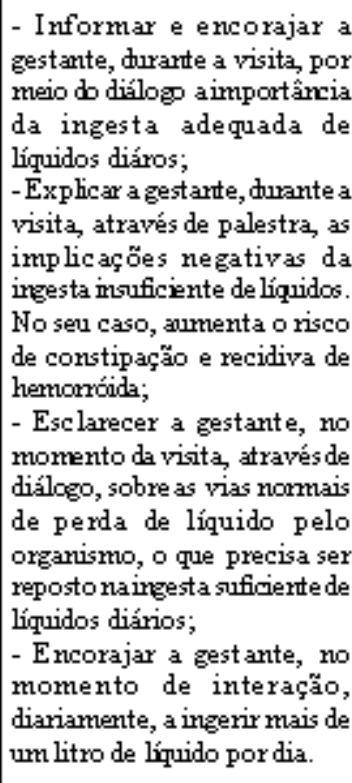 \\
\hline $1^{*}$ dia & Segurança. & $\begin{array}{l}\text { A n s i e d a d e } \\
\text { relacionada a mudan- } \\
\text { ça mo estado de saide, } \\
\text { roudança no anbiente } \\
\text { e a conflitos rela- } \\
\text { cionados a vida pro- } \\
\text { fissional. }\end{array}$ & $\begin{array}{l}\text { Levar a } \\
\text { gestante } \\
\text { a: } \\
\text { - Enfien- } \\
\text { taras si- } \\
\text { tuaçóes } \\
\text { de ansie- } \\
\text { dade. }\end{array}$ & $\begin{array}{l}\text { Levara ges- } \\
\text { tamte a verta- } \\
\text { lizarmenor } \\
\text { ansiedade em } \\
\text { relação a ci- } \\
\text { nurgia, ao } \\
\text { concunso e ao } \\
\text { anbiente. }\end{array}$ & Ensinar. & $\begin{array}{l}\text { A poio - } \\
\text { educação. }\end{array}$ & 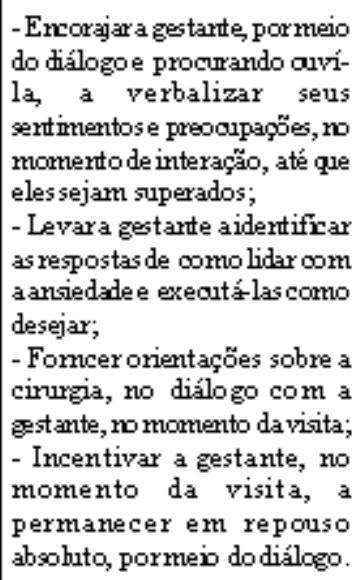 \\
\hline $1^{*}$ dia & Estilo de vida. & $\begin{array}{l}\text { Processo familiar } \\
\text { alterado relacionado a } \\
\text { situação de transição. }\end{array}$ & $\begin{array}{l}\text { Levar a } \\
\text { gestarte } \\
\text { a: } \\
\text { - Enfren- } \\
\text { tar as si- } \\
\text { tuaçóes } \\
\text { de rnu- } \\
\text { danças } \\
\text { noestilo } \\
\text { de vida. }\end{array}$ & $\begin{array}{l}\text { Levara ges- } \\
\text { tante a: ver- } \\
\text { balizar har- } \\
\text { moniano seu } \\
\text { processo fa- } \\
\text { miliar. }\end{array}$ & Ersinar. & $\begin{array}{l}\text { A poio - } \\
\text { educação. }\end{array}$ & 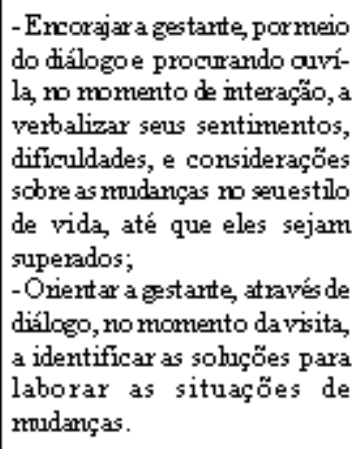 \\
\hline $2^{\circ}$ dia & Communiç̧̄o. & $\begin{array}{l}\text { Comunicaçăo pre- } \\
\text { judicada relacionada } \\
\text { a visco de desconforto } \\
\text { e dor abdominal. }\end{array}$ & $\begin{array}{l}\text { Levara } \\
\text { púrpera } \\
\text { a: } \\
\text { - Dimi- } \\
\text { ruir ris- } \\
\text { cos de } \\
\text { desoorfor- } \\
\text { toe dor } \\
\text { adorinal } \\
\text { por goses. }\end{array}$ & $\begin{array}{l}\text { Levara puér- } \\
\text { pera a: } \\
\text { - Aoeitar a } \\
\text { necessidade } \\
\text { decomuricar- } \\
\text { seatravés da } \\
\text { escrita. }\end{array}$ & $\begin{array}{l}\text { Ensinar, } \\
\text { apoiar e } \\
\text { prover um } \\
\text { ambiente } \\
\text { desenvolvi- } \\
\text { mental. }\end{array}$ & $\begin{array}{l}\text { A poio - } \\
\text { educação e } \\
\text { parciahmen- } \\
\text { tecompen- } \\
\text { satónio. }\end{array}$ & 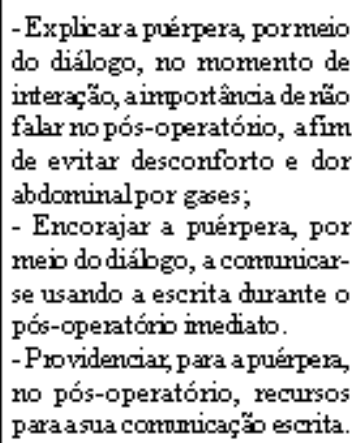 \\
\hline
\end{tabular}




\begin{tabular}{|c|c|c|c|c|c|c|c|}
\hline ATENDIMENTO & $\begin{array}{c}\text { DÉFICIT NO } \\
\text { AUTOCUIDADO }\end{array}$ & $\begin{array}{l}\text { DIAGNÓ STICODE } \\
\text { ENFERMAGEM }\end{array}$ & METAS & OBJEIIVOS & $\begin{array}{l}\text { MÉTODO } \\
\text { DE AJUDA }\end{array}$ & $\begin{array}{l}\text { TIPO DE } \\
\text { SISTEMA }\end{array}$ & $\begin{array}{l}\text { INTERVENÇŎES DE } \\
\text { ENFFERMAGEM }\end{array}$ \\
\hline $2^{\circ} \mathrm{dia}$ & $\begin{array}{l}\text { Integridade da pe- } \\
\text { l. }\end{array}$ & $\begin{array}{l}\text { Risco para integri- } \\
\text { dade da pelepreju- } \\
\text { dicada relacionado a } \\
\text { imobilidade fisica, } \\
\text { urridade e uso interno } \\
\text { de medicamentos. }\end{array}$ & $\begin{array}{l}\text { Manter a } \\
\text { integridade } \\
\text { da pele da } \\
\text { púrpera. }\end{array}$ & $\begin{array}{l}\text { Evitar fato- } \\
\text { res que pre- } \\
\text { judiquem a } \\
\text { integridade } \\
\text { da pela da } \\
\text { puérpera. }\end{array}$ & $\begin{array}{l}\text { Agir ou fa- } \\
\text { zer por e } \\
\text { proporcio- } \\
\text { nar ambiente } \\
\text { desenvolvi- } \\
\text { mertal. }\end{array}$ & $\begin{array}{l}\text { Totahmerte } \\
\text { compensató- } \\
\text { no. }\end{array}$ & $\begin{array}{l}\text { - Massagearas costas da puérpera } \\
\text { com as mãos, a cada duas horas, } \\
\text { virando oseu tórax laterahmente; } \\
\text { - Mamter seco eestirado o lençol } \\
\text { sob a puérpera; } \\
\text { - Promover a troca de curativose } \\
\text { dos lençóis da puérpera, uma vez } \\
\text { ao dia ou quando necessário; } \\
\text {-Observarcontartemente obcal } \\
\text { da infusão venosa da puérpera, } \\
\text { para evitar infiltração de líquidos, } \\
\text { até aretirada da infusão. }\end{array}$ \\
\hline $2^{\circ}$ dia & Proteção. & $\begin{array}{l}\text { Riscopara infecçă, } \\
\text { relacionado a proce- } \\
\text { dimentos invarivos. }\end{array}$ & $\begin{array}{l}\text { Evitar que } \\
\text { a puérpera } \\
\text { tenha in- } \\
\text { fecção. }\end{array}$ & $\begin{array}{l}\text { Reduzir ao } \\
\text { mínimo o } \\
\text { risco de in- } \\
\text { fecção na } \\
\text { púrpera. }\end{array}$ & $\begin{array}{l}\text { Agir ou fa- } \\
\text { zer por e } \\
\text { proporcio- } \\
\text { nar ambien- } \\
\text { te desenvol- } \\
\text { vimertal. }\end{array}$ & $\begin{array}{l}\text { Totahnerte } \\
\text { compensató- } \\
\text { io. }\end{array}$ & $\begin{array}{l}\text { - Estar alerta para sinais de } \\
\text { irfeoção na puérpera, verificando } \\
\text { os seus sinais vitais, duas vezes } \\
\text { ao dia; } \\
\text { - Observar a coloração e } \\
\text { quantidade da urina da puérpera, } \\
\text { drenada pela sonda, a cada oito } \\
\text { horas; } \\
\text { - Realizar huziene íntima na } \\
\text { puérpera, uando água e sabão, } \\
\text { duas vezes ao dia; } \\
\text { - Realizar a troca de curativos e } \\
\text { dos lençóis da puérpera, uma vez } \\
\text { ao diaou quando necessário. } \\
\text { - Manter limpo e seco o local da } \\
\text { infusão venosada puérpera, até a } \\
\text { retrada da infivão. }\end{array}$ \\
\hline $3^{*}$ dia & $\begin{array}{l}\text { Conhecimento } \\
\text { sobre deambu- } \\
\text { lação precoce e } \\
\text { nudamçade decú- } \\
\text { bito. }\end{array}$ & $\begin{array}{l}\text { Mobilidade fís ca } \\
\text { prejudicada, rela- } \\
\text { cionada ao processo } \\
\text { cinirgico. }\end{array}$ & $\begin{array}{l}\text { Levar a } \\
\text { puérpera a } \\
\text { alcançar } \\
\text { mobiliade } \\
\text { fisica sa- } \\
\text { tisfatónia. }\end{array}$ & $\begin{array}{l}\text { Levara puér- } \\
\text { pera: } \\
\text { - Reconhe- } \\
\text { ceraimpor- } \\
\text { t ância da } \\
\text { mobilidade } \\
\text { f́́sica para } \\
\text { sua recupe- } \\
\text { ração; } \\
\text { - Realizar a } \\
\text { mobilidade } \\
\text { fíca. }\end{array}$ & $\begin{array}{l}\text { Envinar, agir } \\
\text { ou fazer por } \\
\text { e ajudar. }\end{array}$ & $\begin{array}{l}\text { A poio - } \\
\text { educação e } \\
\text { parciahmen- } \\
\text { te compen- } \\
\text { satónio. }\end{array}$ & 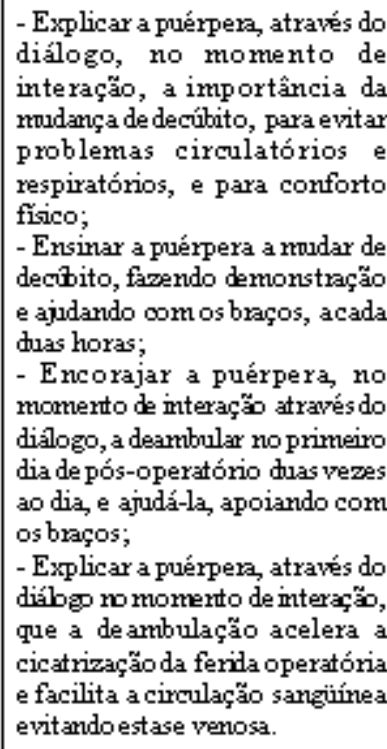 \\
\hline $3^{*} \mathrm{dia}$ & Higiene. & $\begin{array}{l}\text { Déficit no autocui- } \\
\text { dado: higiene cor- } \\
\text { poral relacionado a } \\
\text { dorou desconfortoe } \\
\text { força e resistência } \\
\text { dimiruidas. }\end{array}$ & $\begin{array}{l}\text { Superar a } \\
\text { difiouldade } \\
\text { dapuérpe- } \\
\text { raem rea- } \\
\text { lizar sua } \\
\text { higiene } \\
\text { corporal. }\end{array}$ & $\begin{array}{l}\text { Levara puér- } \\
\text { pera a reali- } \\
\text { zar a sua hi- } \\
\text { giene corpo- } \\
\text { ral. }\end{array}$ & $\begin{array}{l}\text { Agir ou fa- } \\
\text { zer por, aju- } \\
\text { dar. }\end{array}$ & $\begin{array}{l}\text { Parciahmen- } \\
\text { te compen- } \\
\text { satóni. }\end{array}$ & $\begin{array}{l}\text { - Providenciar marnutenção de } \\
\text { ambiente limpo e seguro para a } \\
\text { higierização da puérpera; } \\
\text { - Ajudar a puérpera locomover- } \\
\text { se até ao banheiro, apoiando oom } \\
\text { os braços, quando necessário; } \\
\text { - Prover assist ência durante a a } \\
\text { execução da higjene corporal da } \\
\text { puérpera, lavando o seu corpo, } \\
\text { uma vez ao dia. }\end{array}$ \\
\hline $3^{*} \mathrm{dia}$ & $\begin{array}{l}\text { Vestir e amumar- } \\
\text { se. }\end{array}$ & $\begin{array}{l}\text { Deficitno aubcuida- } \\
\text { do: vestir-se e ar- } \\
\text { rumar-se relacionado } \\
\text { a dor ou desconforto } \\
\text { e força e resistência } \\
\text { dimiruida. }\end{array}$ & $\begin{array}{l}\text { Superar a } \\
\text { difiouldade } \\
\text { da puér- } \\
\text { pera em } \\
\text { vestir-se e } \\
\text { amumar- } \\
\text { se. }\end{array}$ & $\begin{array}{l}\text { Levara puér- } \\
\text { pera vestir- } \\
\text { se a arumar- } \\
\text { se. }\end{array}$ & $\begin{array}{l}\text { Agir ou fa- } \\
\text { zer por, aju- } \\
\text { dar. }\end{array}$ & $\begin{array}{l}\text { Parciahnen- } \\
\text { te compen- } \\
\text { satónio. }\end{array}$ & $\begin{array}{l}\text { - Assistir a puérpera no momerto } \\
\text { de vestíla ajudando-a a vestir-se } \\
\text { e a ammar-se, qaundo neossário } \\
\text { - Manter a privacidade da } \\
\text { puérpera ao vestí-la, evitando a } \\
\text { entrada de pessoas estranhas. }\end{array}$ \\
\hline
\end{tabular}




\begin{tabular}{|c|c|c|c|c|c|c|c|}
\hline ATENDIMENTO & $\begin{array}{c}\text { DÉFICIT NO } \\
\text { AUTO CUIDADO }\end{array}$ & $\begin{array}{l}\text { DIAGNÓ STICODE } \\
\text { ENFER MAGEM }\end{array}$ & METAS & OBJEIIVOS & $\begin{array}{l}\text { MÉTODO } \\
\text { DE AJUDA }\end{array}$ & $\begin{array}{l}\text { TIPO DE } \\
\text { SISTEMA }\end{array}$ & $\begin{array}{l}\text { INTERVENÇŎES } \\
\text { DE ENFERMAGEM }\end{array}$ \\
\hline $3^{\circ} \mathrm{dia}$ & Eliminaç̃̃o. & $\begin{array}{l}\text { Retençăo urinária } \\
\text { relacionada a inibi- } \\
\text { ção do aroo reflexoe } \\
\text { contração do es- } \\
\text { fincter. }\end{array}$ & $\begin{array}{l}\text { Levar a } \\
\text { puérpera a } \\
\text { adotar ou- } \\
\text { tras manei- } \\
\text { raspara fa- } \\
\text { cilitar a } \\
\text { micção, } \\
\text { além da } \\
\text { sondagem } \\
\text { vesical. }\end{array}$ & $\begin{array}{l}\text { Levar a puér- } \\
\text { pera a verba- } \\
\text { lizar micção } \\
\text { nomal. }\end{array}$ & $\begin{array}{l}\text { Ensinar e } \\
\text { promover } \\
\text { ambiente } \\
\text { deserwolvi- } \\
\text { mertal. }\end{array}$ & $\begin{array}{l}\text { A poio - } \\
\text { educação. }\end{array}$ & 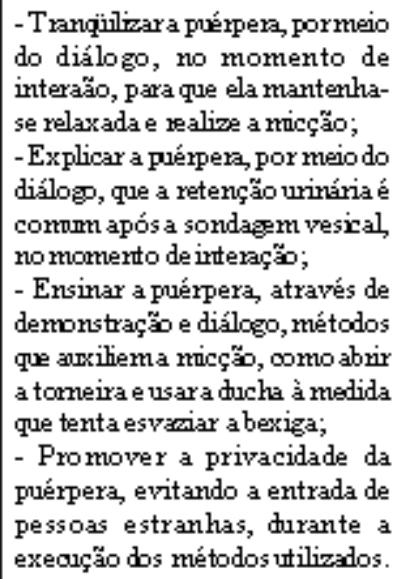 \\
\hline $3^{\circ} \mathrm{dia}$ & Corforto. & $\begin{array}{l}\text { Dor relacionada ao } \\
\text { trauma cirúrgico e } \\
\text { acirnulo de gases no } \\
\text { abdome. }\end{array}$ & $\begin{array}{l}\text { Levar a } \\
\text { puérpera a } \\
\text { usar téc- } \\
\text { nicas para } \\
\text { diminuir a } \\
\text { dor. }\end{array}$ & $\begin{array}{l}\text { Levar a puér- } \\
\text { pera a verba- } \\
\text { lizar dimirui- } \\
\text { ção da dor. }\end{array}$ & $\begin{array}{l}\text { Ensinar ou } \\
\text { agir ou fa- } \\
\text { zor por. }\end{array}$ & $\begin{array}{l}\text { A poio - } \\
\text { educação. }\end{array}$ & $\begin{array}{l}\text {-Eninara puérpera, no momerto } \\
\text { de inetração e diálogo, a utilizar } \\
\text { técnic as para dimirnir a dor, } \\
\text { fazendo demonstração; } \\
\text { - Encorajara puérpera, através de } \\
\text { conversa, no mo me nto de } \\
\text { interação, a utilizar as técricas } \\
\text { para dimirnir a dor, co mo } \\
\text { deambulação precoce, roudança } \\
\text { dedeoúbito e respiração profumda, } \\
\text { e ajudar, se necessário. }\end{array}$ \\
\hline $3^{\circ}$ dia & $\begin{array}{l}\text { Conhecimento } \\
\text { sobre amamenta- } \\
\text { çăo }\end{array}$ & $\begin{array}{l}\text { Amamentaçăo ine- } \\
\text { ficas relacionada a } \\
\text { déficit de conheci- } \\
\text { mento. }\end{array}$ & $\begin{array}{l}\text { Levar a } \\
\text { puérpera a } \\
\text { amamen- } \\
\text { tar o seu } \\
\text { filhode for- } \\
\text { maeficaz. }\end{array}$ & $\begin{array}{l}\text { Levar a puér- } \\
\text { peraa realizar } \\
\text { amamentação } \\
\text { eficaz. }\end{array}$ & $\begin{array}{l}\text { Ensinar, } \\
\text { a judar, } \\
\text { promover } \\
\text { ambiente } \\
\text { deservolvi- } \\
\text { mertal. }\end{array}$ & $\begin{array}{l}\text { A poio - } \\
\text { educação e } \\
\text { parciahmen- } \\
\text { tecompen- } \\
\text { satónio. }\end{array}$ & $\begin{array}{l}\text {-Explicara puérpera, no momento } \\
\text { de interação, através de diálogo, } \\
\text { sobre aprodŗão do leite loumano } \\
\text { e a importância da sucção da } \\
\text { mama pela criança; } \\
\text { - Trazer a criança para que a } \\
\text { puérpera a amamente, } \\
\text { promovendoe inoentivando alivre } \\
\text { demanda; } \\
\text { - Promover ambiente tranquilo } \\
\text { para que a puérpera amamente, } \\
\text { não pe rmit indo barulho } \\
\text { demaiado; } \\
\text { - Encorajar a puérpera para a } \\
\text { amamentação exchsiva, através } \\
\text { de diálogo, no momento de } \\
\text { interação. }\end{array}$ \\
\hline
\end{tabular}

\subsubsection{Implementação da assistência de enfermagem}

$1^{\mathrm{o}}$ dia - Domicílio - A gestante foi informada sobre a importância dos líquidos para o corpo humano e sobre as implicações negativas da ingesta insuficiente de líquidos para o organismo. Ela aumentou sua ingesta de líquidos, expressou suas ansiedades e sentimentos, e permaneceu em repouso absoluto, mostrando ter iniciado seu processo de autocuidado.

$2^{\circ}$ dia - Domicílio / Maternidade - A gestante manteve a ingesta de líquidos e o repouso absoluto. Por volta do meio dia, quando estava no banheiro, apresentou sangramento vaginal intenso, o que a levou a ser submetida a uma cesária de emergência, antes mesmo de ter sido orientada sobre a mesma. Acompanhei a paciente até a maternidade onde foi realizada a cesária, porém não pude permanecer ao seu lado durante a cirurgia, por falta de permissão da Direção. A cirurgia foi realizada às 15:20', transcorreu bem, sem transtorno. O recém-nascido foi levado ao berçário para os cuidados imediatos; ele estava bem. Ao sair da sala de cirurgia, a puérpera apresentava-se chorosa, relatando que teve medo da cirurgia, pois ficou sozinha, sem nenhuma pessoa querida por perto. Perguntava pelo seu filho. Estava com sonda vesical de demora e soro instalado no antebraço direito. Seus familiares a aguardavam no apartamento. Ela foi informada sobre o estado de saúde do seu filho, e tranquilizada ao ser explicado que tudo transcorreu bem na cirurgia. Foi orientada a não falar, a fim de evitar acúmulo de gases no abdome, incentivada a comunicarse através da escrita, e providenciado lápis e papel para que ela pudesse comunicar-se. Foi dada atenção a infusão 
venosa, com vistas a evitar infiltração tissular de líquidos e infecção, procurando manter limpo e seco o local. A sondagem vesical não apresentou complicações. Mais tarde, o curativo apresentava-se umedecido por sangue. Foi providenciado asseio vaginal e a troca de curativo e dos lençois, atentando para não deixar dobras, para evitar pruridos e escaras. Temperatura $36,5^{\circ} \mathrm{C}$, Pulso $80 \mathrm{bpm}$ e PA 110 x $70 \mathrm{mmHg}$. Passou a noite bem. Em relação à sua comunicação, a paciente ora escrevia as queixas e solicitações, ora esquecia ou não se continha, e falava.

$3^{\circ}$ dia - Maternidade - Ao amanhecer, foi retirada a sonda vesical e suspensa a infusão venosa. Havia cerca de um litro de urina drenada, com aspecto e coloração fisiológicos. O local da infusão não apresentava infiltração de líquidos. A puérpera foi ajudada a sentarse na cama. Ingeriu, de forma fracionada, um copo de água. Seu banho foi preparado. Ela foi ajudada a locomover-se para o banheiro, onde foi auxiliada no banho e a vestir-se. Alimentou-se de todos os alimentos oferecidos (fruta, pão, papa de aveia, queijo, leite e café). Queixava-se de sensação de bexiga cheia, mas não conseguia urinar. Orientada a abrir a torneira, usar a ducha e procurar relaxar, para facilitar a micção, assim o fez. Foi mantida a sua privacidade. Aos poucos, em pequena quantidade, sua bexiga foi sendo esvaziada até recuperarse, por volta das 10:00. Seu filho foi trazido para a sua companhia. Com ajuda, ela o colocou ao seio. O bebê apresentava boa sucção, mas ainda não tinha leite. Ela foi orientada que a sucção do bebê estimulava a produção do leite e sua descida. Assim procedeu ao longo do dia. A incisão cirúrgica apresentava-se seca e sem sangramento. Apresentava distensão abdominal e queixava-se de dor e desconforto. Foi orientada sobre a importância da deambulação precoce para a eliminação de gases, funcionamento do intestino, cicatrização cirúrgica e circulação sangüínea. Ela realizou a deambulação com auxílio. Durante o dia a puérpera alimentou-se bem, urinou várias vezes e deambulou. Ingeriu cerca de dois litros de líquidos, incluindo água, sucos, leite e café. A noite acordou algumas vezes, para, com auxílio, amamentar o filho. Observou-se que a paciente regulava suas atividades de autocuidado, aceitava atendimento e auxílio do enfermeiro e realizava algumas atividades de autocuidado, com exceção de evitar conversar.

$4^{\circ}$ dia - Maternidade - Ao amanhecer, foi auxiliada a locomover-se para o banho e a vestir-se. Alimentou-se bem. Ainda apresentava-se com distensão abdominal. As orientações do dia anterior foram reforçadas. Presença de colostro nos seios. Foi incentivada para a amamentação exclusiva do seu filho, em livre demanda; ela mostrou-se determinada para tal, pois já havia amamentado o outro filho com sucesso. Recebeu alta hospitalar. Deixou a maternidade às 10:15'.

\section{AVALIAÇÃO GERAL}

No decorrer da implementação da assistência de enfermagem e a sua avaliação, constatou-se que muitas vezes o paciente não está consciente da importância da realização do AC para a manutenção da sua vida, saúde e bem-estar. Nesse caso em particular, a paciente, em algumas ocasiões, era conhecedora dessa necessidade. Porém, necessitava ser orientada e incentivada a executá1o. Observou-se, também, que não é utópico desenvolvimento do Autocuidado pela paciente, e que isto envolve, acima de tudo, decisão da mesma. Pode-se dizer que, com sucesso, a meta primordial deste estudo, que foi levar a paciente a realizar o Autocuidado, foi alcançada.

\section{CONSIDERAÇÕES FINAIS}

Durante a gravidez a mulher passa por diversas mudanças, ocasionando algumas demandas e déficits de autocuidado, que precisam ser compensadas e supridos de forma a preservar o seu bem-estar e manter a sua saúde. Nesse sentido, o enfermeiro ocupa um papel importante no acompanhamento às gestantes de baixo e de alto risco, que necessitam de recomendações e cuidados para que a gestação chegue a termo, a fim de prevenir a prematuridade e ou riscos à sua saúde e a do concepto. Para tanto, a gestante deve ser incentivada a engajar-se no autocuidado, devendo compreender a natureza da assistência e os fatores intervenientes na mesma.

Acerca dos resultados obtidos, houve possibilidade de identificar, pela assistência embasada no modelo teórico de OREM, os déficits de autocuidado universais, de desenvolvimento e de desvios de saúde, que levaram aos seguintes diagnósticos de enfermagem: Déficit de volume de líquido; Ansiedade; Processo familiar alterado; Comunicação prejudicada; Risco para integridade da pele prejudicada; Risco para infecção; Mobilidade física prejudicada; Déficit no autocuidado: higiene corporal; Déficit no autocuidado: vestir-se e arrumar-se; Retenção urinária; Dor; e Amamentação ineficaz.

Os resultados permitiram também a identificação da ocorrência, numa mesma paciente, dos três Sistemas de Enfermagem de OREM. Através dos resultados obtidos, o método de ajuda foi selecionado, e relacionado o Sistema de Enfermagem, expressando o papel do enfermeiro e a capacidade da paciente em engajar-se no autocuidado. Acredita-se que os resultados deste estudo possam contribuir para o despertar do enfermeiro quanto as suas responsabilidades em cuidar e atender os requisitos para o autocuidado terapêutico dos seus pacientes. 
Por ultimo, vale destacar que este estudo mostrou a importância da assistência à gestante de alto risco baseada na Teoria do Autocuidado de OREM, quando houve a adesão da paciente às medidas terapêuticas prescritas, fato observado através de sua tomada de decisão, controle e condução da assistência.

Ademais, evidenciou-se com a realização deste estudo, a importância de se operacionalizar o processo de enfermagem tendo por base um modelo assistencial, a fim de facilitar a identificação de diagnósticos de enfermagem, bem como o desenvolvimento da sua prática. Ficou evidente, também, que o autocuidado é algo aprendido, e que a gestante faz parte de um grupo ideal para que o processo de aprendizagem se realize.

\section{NURSING DIAGNOSES IN HIGH-RISK PREGNANT WOMEN BASED ON OREM'S SELF- CARE THEORY - A CASE STUDY}

This work concerns a descriptive research with a qualitative approach which aimed to identify nursing diagnoses in high-risk pregnant women based on Orem's self-care theory. The following nursing diagnoses were identified: deficit of liquid volume, anxiety, altered family process, handicapped communication, handicapped physical mobility, among others. The results showed the importance of the nursing process execution supported on an assistance pattern, for the identification of nursing diagnoses as well as the feasibility of the patient's engagement in self-care.

KEY WORDS: nursing diagnostics, pregnancy high-risk, self-care

\section{DIAGNÓSTICOS DE ENFERMERÍA EN UNA GESTANTE DE ALTO RIESGO BASADOS EN LA TEORIA DEL AUTOCUIDADO DE OREM}

Investigación descriptiva con un abordaje cualitativo, realizada con el objetivo de identificar diagnósticos de enfermería en una gestante de alto riesgo, basados en la teoría del autocuidado de Orem. Fueron identificados los siguientes diagnósticos de enfermería: déficit de volumen de líquidos, ansiedad, proceso familiar alterado, comunicación perjudicada, movilidad física perjudicada, entre otros. Los resultados mostraran la importancia de la ejecución del proceso de enfermería, apoyado en un modelo de atención, para la identificación del diagnóstico de enfermería, así como también la viabilidad del paciente adaptarse al proceso de autocuidado.

TÉRMINOS CLAVES: diagnóstico de enfermería, embarazo de alto riesgo, autocuidado

ANEXO 1

\section{ROTEIRO DE ENTREVISTA}

\section{ASPECTOS DA TEORIA DE OREM A SEREM OBSERVADOS \\ 1. FATORES CONDICIONANTES}

Idade Escolaridade Altura Peso

atual Profissão/ocupação

Procedência Estado civil

D.U.M. Gesta Idade dos Filhos

$\mathrm{N}^{\mathrm{o}}$ de filhos vivos I.G.

2. DEMAND $\overline{A S}$ TERAPEUTICAS $\overline{\text { PARA }}$ AUTOCUIDADO (AC)

REQUISITOS UNIVERSAIS

Quais são os alimentos presentes na sua alimentação? Desjejum, Almoço e Jantar

Eliminação e excreção:

- Urina: Quantas vezes você urina por dia? Qual a cor e odor? Qual a quatidade?

- Fezes: Quantas vezes você evacua por dia? Quais as características das fezes?

Equilíbrio entre atividade e descanso:
- Tem dificuldade em satisfazer as necessidades de sono e repouso?

- Dorme quantas horas por dia? As horas de sono que dorme são suficientes para o repouso?

- Trabalha quantas horas por dia?

Equilíbrio entre solidão e interação social:

- A gravidez interferiu no seu relacionamento com as demais pessoas?

- Você sente momentos de tristeza e/ou choro? Em que circunstância?

Avaliação: Demanda de AC ( ) Sim Relacionada a:

$$
\text { ( ) Não }
$$

Capacidade de AC demanda de AC REQUISITOS DE DESENVOLVIMENTO

Você já fez algum exame nesta gestação? Qual(is)? Quando? Pelos resultados dos exames é uma gravidez de risco? Porque? Você compareceu a todas as consultas marcadas? Como você percebe esta gravidez?

Há algum evento na sua vida que a tem preocupado e/ou está lhe preocupando? Gostaria de falar?

Avaliação: Demanda de AC ( ) Sim Relacionada a:

$$
\text { ( ) Não }
$$

Capacidade de AC demanda de AC

REQUISITOS DE DESVIO DE SAÚDE

Em caso de Gestação de Risco: 
Você apresentou algum problema nesta gravidez? O que? Quando? Qual a conduta médica?

Você conhece a natureza e as conseqüências deste problema? Em relação ao preparo para o parto, você já recebeu alguma orientação? Quais são os seus anseios?

Avaliação: Demanda AC ( ) Sim Relacionada a:

$$
\text { ( ) Não }
$$

Capacidade de AC demanda de $\mathrm{AC}$
Observações da pesquisadora, durante a entrevista e em avaliações subseqüentes (s/n): (estado geral, gestos e expressão. motivação para o autocuidado, etc)

$\overline{\text { Assinatura da pesquisadora }}$ COREN/PB

\section{REFERÊNCIAS BIBLIOGRÁFICAS}

01. ARAÚJO, C.R.D. de. Autocuidado na utilização de medicamentos cardiovasculares: proposta educativa de enfermagem. João Pessoa, 1996. 139p. Dissertação (Mestrado em Enfermagem). Universidade Federal da Paraíba.

02. BARROS, A.C.S.D. de. Fisiopatologia das principais causas de óbito materno. In: FAÚNDES, A.; CECATTI, J. G. Morte materna: uma tragédia evitável. 2. ed. Campinas: Editora da UNICAMP, 1991. p. 119-138.

03. BRASIL. Ministério da Saúde. Módulos das ações básicas de assistência integral à saúde da mulher e da criança. Brasília, 1984. 73 p.

04. FOSTER, P.C.; JANSSENS, N.P. Dorothea E. Orem. In: GeORGE, J.B. et al. Teorias de Enfermagem: os fundamentos para a prática profissional. Porto Alegre: Artes Médicas, 1993. p. 90-107.

05. IYER, P.W.; TAPTICH, J.B.; BERNOCCHI-LOSEY, $D$. Processo e diagnóstico em enfermagem. Porto Alegre: Artes Médicas, 1993. 325 p.
06. NETTO, H.C. et al. Prevenção da morte materna na gestação de alto risco. In: FAÚNDES, A.; CECATTI, J.G. Morte materna: uma tragédia evitável. 2. ed. Campinas: Editora da UNICAMP, 1991. p. 99-118.

07. OREM, D.E. Nursing: concepts of practice. 4. ed. Saint Louis: Mosby, 1991.

08. PEIXOTO, M.R.B. Divergências e convergências entre um modelo de assistência de enfermagem a pacientes diabéticos e a teoria do déficit de autocuidado de Orem. Rev. Esc. Enfermagem USP, v. 30, n. 1, p. 1-13, abr. 1996.

09. REZENDE, J. de.; MONTENEGRO, C.A.B. Obstetrícia fundamental. 7. ed. Rio de Janeiro: Guanabara, 1995.Caps. 5, p. 69-84: Modificações do organismo materno.

10. REZENDE, J. de.; MONTENEGRO, C.A.B. Obstetrícia fundamental. 7. ed. Rio de Janeiro: Guanabara, 1995.Caps. 22, p. 265-271: Placenta prévia.

11. ROSSI JÚNIOR, R. Metodologia científica para a área da saúde. São Paulo: Pancast, 1990. 108p. 